compliance with the Food and Drugs Acts, Labelling of Food Orders I953 with Amending (Scotland) Regulations of 1956.

\title{
Some reflections
}

From official reports on food-borne illness, it seems evident that most cases are due to post-mortem or post-milking bacterial contamination by man, animals, or insects. It is expected that the practice of food hygiene will eventually control such infections, but until then, the measurement of progress may be by bacteriological food sampling.

The sanitary inspector has already been given the necessary legal powers which he should use specifically and with the utmost discretion. On the other hand, will the solution be ultimately provided by the use of antibiotics or controlled exposure to radioactive sources? Are we indeed now reaching the age when fish will no longer require inspecting for infections, freshness, or excess preservative, but will be 'frisked' for radioactive contamination from the waters around the nuclear power stations?

\section{The viewpoint of catering management}

By E. W. G. Guest, foint Managing Director, Macvitties Guest and Company

\author{
Limited, Princes Street, Edinburgh
}

I should like to open my remarks by saying that I intend to deal with the subject of 'clean food', and to show the methods used by caterers at the present time to further this aim.

\section{Education in hygiene}

Clean-food hygiene must begin with instructions to the staff as regards clean personal habits, that is, scrupulous attention to washing of hands and finger nails, and to the condition of hair which should always be kept tidy. Caps should be worn, wherever possible, for work in kitchens and other preparation rooms. The present fashion for short, neat hair styles is a great help in this connexion.

The greatest advances will be made as hygiene improves and is learnt automatically in more and more homes and schools, so that when a boy or girl goes to a technical college and finally into a catering business, it will be unnecessary to teach such elementary rules.

The Hotel and Catering Institute has assumed responsibility for the setting up of classes for the training of students at colleges and educational institutes throughout Great Britain. It has a graded system of examinations, and the student can only progress into a higher grade when he has satisfied the examiners that he is proficient in all subjects. 
In Edinburgh, the School of Baking and Catering receives considerable help from officials of the Public Health Department, one useful aid being the loan of films specially made for students. The Head Instructor at this School told me that he lays particular stress on hygiene in all his lectures and demonstrations.

The new Hygiene Regulations contain a paragraph which makes the provision of washhand basins in rooms where food is prepared a statutory obligation. Once these have been installed, one will also have to see that the staff adopts the habit of using them.

\section{Restaurants and snack bars}

Keeping of prepared food. The present-day methods of storing food are made simpler by the use of stainless steel containers, kept hot by steam, gas or electricity, and by the modern practice of using infra-red electric bulbs. Cold food is kept really cool and at an even temperature in refrigerated cabinets.

Service to the customers. Here again, hygiene largely depends on the correct training of waitresses, both in personal hygiene and in the correct handling of plates, cups and glasses. All food should be lifted with tongs where possible. In snack bars, which are becoming popular because of their quick service and low prices, there are some problems to be solved owing to the close proximity of the food to the public. In order to ensure speedy service, most of the food is laid out on some form of tray on the counter itself. There are now on the market glass-fronted cases with flaps which can be lifted by the customer when making his choice. These must be kept as simple as possible, as they tend to slow down the speed of the queue. Plastic materials are now very popular, and are widely used on tables and counters. Provided they are cleaned frequently, they are very hygienic. Cloths used for wiping must be kept clean and boiled regularly, otherwise they may quickly become potential breeding grounds for bacteria, and may make a table 'dirtier' than it was before 'cleaning'.

Considerable strides have been made in recent years in the provision of machines for dish washing. These are mainly of two types. (I) The brush and dip type in which the dishes are dipped into water and held by hand against revolving brushes, after which they are placed in racks immersed in the separate sterilizing compartment, with thermostatically controlled temperature. The dishes dry in the racks, and are untouched by hand. (2) Larger establishments are catered for by the automatic type of machine. In this machine, trays of crockery are carried through on a roller conveyor. First, the dishes receive a powerful all-over hot-solution wash, directed both from above and below, and then a fine scalding rinse in a separate chamber, ensuring sterile, quick-drying crockery. Detergents and sterilizing agents used with these machines have improved tremendously since the war.

The standard of hygiene in catering establishments is, I think, quite high, and most caterers are only too willing to do their best to make improvements. The provision of up-to-date equipment is an expensive business, and most firms find it extremely difficult under present-day credit restrictions. Caterers would be helped in their task if the public would do their share. Litter of all kinds is dropped on the floor 
and cigarette ash scattered indiscriminately, no matter how many ashtrays are provided.

\section{Food poisoning}

Statistics for the incidence of food poisoning are not yet available for Scotiand, as there was no legal obligation on the part of doctors to report these outbreaks until August 1956, when the Food and Drugs (Scotland) Act came into operation.

The last year for which there are complete statistics for England and Wales is I955. Family outbreaks are not included, because it is difficult to get sound information about them, but, in catering establishments, the number of outbreaks was 287 . Of these, rog occurred in school, works and services canteens, $3^{I}$ in institutions, 17 at private parties, 24 in restaurants and 37 were traced to shops, such as butchers, bakers, cooked-meat shops, grocers and dairies.

In 1953 , the figure for restaurants and clubs was 42 , and one hopes that this downward trend will continue.

In these and other incidents of food poisoning reported during the year, the number of patients involved was about 20,000, with $5 \mathrm{I}$ deaths. Much as one regrets even this number, it is small by comparison with the number of people who die from accidents at home (about 6600) and the 5000 who are killed each year on the roads.

\section{Clinical consequences of food poisoning as illustrated by a recent outbreak}

\section{By A. W. WRIGHT, Bangour Hospital, Broxburn, West Lothian, Scotland}

Food poisoning is the subject of some 200 or 300 publications in the medical press in each year, of which only a very small number deal with its clinical aspects. Its main interest to the hospital physician is in its influence as a complication on pre-existing disease and in the disruption of the hospital service which it may produce. It is believed that the symptoms are predominantly gastro-intestinal, that the diagnosis is always a simple matter, and that in any event the disease is fortunately self-limiting. Such optimism may be misplaced, for the early symptoms in the first cases in an outbreak may be quite misleading, and pyrexia and abdominal pain may precede by several hours the onset of diarrhoea and vomiting.

Furthermore, food poisoning may be a very severe disease in the young and in the aged, and mortality figures as high as $5 \%$ have been recorded, although $0.1 \%$ in the series of cases in the United States some years ago probably gives a better overall picture (Seligmann, Saphra \& Wassermann, I946). In addition, these infections are not uncommon in hospitals and other institutions, and their impact on a sick or infirm population may be disastrous.

The clinical features of the infection vary to some extent with the infecting organism. In staphylococcal food poisoning, for example, the symptoms come on suddenly and only 2 or $3 \mathrm{~h}$ after eating the contaminated food the patient is struck 